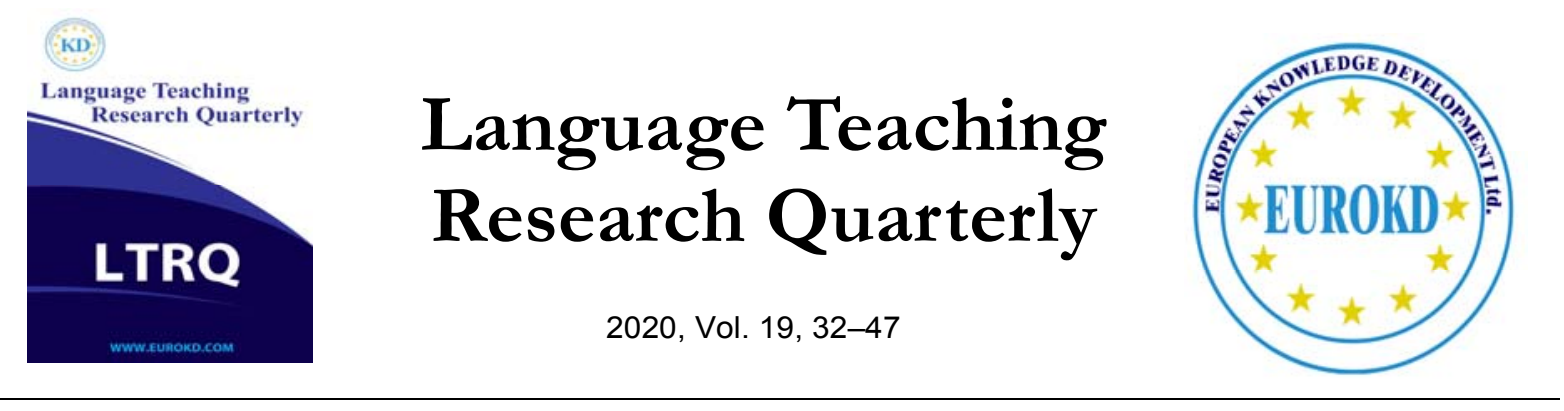

\title{
Assisting Learners in Orchestrating their Inner Voice for L2 Learning
}

\author{
Brian Tomlinson \\ University of Liverpool, UK, Anaheim University, USA \\ Special Issue: Pathways to the Successful Teaching and Learning of an L2 \\ In Honor of Andrew Cohen's Contributions to L2 Teaching and Learning Research
}

Received 15 November $2019 \quad$ Accepted 25 April 2020

\begin{abstract}
In our L1 the person we talk to more than anybody else each day is ourself. We talk to ourselves all the time using our inner voice, both during our waking hours and in our dreams. We do so in order to make sense of the world, to understand what we see, read and hear, to comment and evaluate, to make decisions, to support ourselves, to entertain ourselves, to control our emotions, to decide and rehearse what to say or write. Without using our inner voice we would be much less capable of interacting with the world and with other people. For example, right now I am using my inner voice to dictate to my fingers what to type and then I am using it to read and comment on what I have just typed. How would I do that without my inner voice?
\end{abstract}

Keywords: Inner voice, L2 Learning

\section{Introduction}

In our L1 the person we talk to more than anybody else each day is ourself. We talk to ourselves all the time using our inner voice, both during our waking hours and in our dreams. We do so in order to make sense of the world, to understand what we see, read and hear, to comment and evaluate, to make decisions, to support ourselves, to entertain ourselves, to control our emotions, to decide and rehearse what to say or write. Without using our inner voice we would be much 
less capable of interacting with the world and with other people. For example, right now I am using my inner voice to dictate to my fingers what to type and then I am using it to read and comment on what I have just typed. How would I do that without my inner voice?

When we are learning an L2 the person we typically talk to most in the L2 is our teacher. We do so in order to answer questions, to practice language forms, to demonstrate understanding (or lack of understanding), to display our ability (or hide our lack of it), and sometimes to actually have a conversation. We very rarely use the L2 to talk to ourselves and thus fail to make use of the amazing learning resource of the inner voice when we are engaged in learning or trying to use our L2. As Tomlinson and Masuhara (2020) say:

In the L1 we talk to ourselves all the time using our inner voice. We do so to make decisions, to decide on a stance, to amuse ourselves, to vent our spleen, to be creative, to make plans and preparations, to help us to understand what we have read or heard, to prepare for outer speech and to help us to control what we say to other people. We do all this in a highly efficient restricted code which features simple tenses, the active voice, a basic vocabulary, ellipsis, incomplete utterances and utterances completed by visual imagery. Yet research shows that L2 learners rarely use L2 inner speech until they attain a high level of communicative competence, thus depriving themselves of opportunities to generate communicative output which can become valuable auto-input.(Tomlinson \& Masuhara,2020)

Not only do L2 learners typically deprive themselves of opportunities to generate communicative outputand to acquire language by not using their inner voice, they also make it much more difficult and much less effective when they try to read, write, speak or listen in their L2. By the inner voice, I mean what we use to produce sound in our mind, be it when reading a text mentally, repeating a word or phoneme in the mind or actually talking to ourselves. By inner speech I mean using the inner voice to talk to ourselves.

As you might have gathered by now I am a great believer in helping L2 learners to make use of their inner voice both to communicate and to acquire and the main aim of this article is to stimulate teachers to develop activities which will promote learner employment of their inner voice during L2 learning and use.

\section{What Is the Inner Voice?}

The inner voice is what we use to produce sounds in our head. Try singing a song without producing external sounds, or mentally humming a tune or imitating a barking dog, or talking to yourself about what you think we use the inner voice for. What is happening is that the tongue is approximating articulation. It moves towards articulation points in the mouth without actually making contact. Children, and sometimes adults, actually do articulate the sounds externally and produce what is called private speech when talking aloud to themselves. Guerrero $(2017$, p. 1) refers to inner speech as IS and private speech as PS and defines 'IS as 'silent speech for oneself' and PS as 'externalized speech for oneself'. Guerrero (2017, p. 6) also refers to a widely held view that IS is 'a dual-natured phenomenon consisting of an articulatory (inner voice or inner 
speaking) and an auditory (inner ear or inner hearing) component, both part of the phonological loop system.'

Inner speech is not external speech minus articulation. It is a related but distinct phenomenon it itself. For example, 'although IS and external speech share certain brain regions typically associated with language processing (such as Broca's and Wernicke's areas), other distinct areas and networks of activation have been detected for covert and overt speech' (Guerrero, 2017, p. 7). In addition the grammar of inner speech and of external speech differ considerably (Wiley, 2006). Tomlinson (2000, p. 125) claims that inner speech is a restricted but highly effective linguistic code which follows the brain's basic principle of economy. It is typically 'elliptical, vague, implicit, concrete, descriptive and narrative', 'it uses a narrow range of vocabulary and structures' and 'relies to a great extent on such verbal features as intonation and stress'. And, probably most significant in relation to the development of an L2 inner voice, because it is not monitored by other people ${ }^{6}$ we do not worry about false starts, repetitions and apparent grammatical inconsistencies. We know what we mean'. Tomlinson (2000, p. 125-133) makes use of the inner speech diaries of sixteen of his students at the National University of Singapore, of their responses to inner speech questionnaires, of his own inner speech diary and of the findings of such researchers as Sokolov (1972) to list the following characteristics of inner speech.

Inner speech is often:

- elliptical in that utterances are often not in complete sentences (e.g. 'Alright, nothing very unusual.');

- exophoric in that reference is nearly always to a known context rather than to words or phrases in other utterances (e.g. 'Why did I do that?);

- implicit in that gaps are filled 'with sensory and affective connections and with contextual and contextual reference' (Tomlinson, 2000, p. 128) (e.g. 'Is money everything?');

- incomplete in that utterances are not finished as a result of a change of focus, of predictability or of completion being achieved by a visual image (e.g. 'I'll go by ...' (+ visual image of a train);

- vague because there is no need to achieve the precision required by external communication with others (e.g. 'Weird. Doesn't make sense.');

- narrow (e.g. in Tomlinson's NUS corpus 'the average length of the utterance is four words, all the utterances are in the active voice, nearly all of them have simple aspect, none of them have perfective aspect, none of them contain a subordinate clause ...' (Tomlinson, 2000, p. 130);

- new in the sense that we often do not need to articulate the subject and focus instead on the predicate and on the comment rather than the topic (e.g. 'Must be written by a kid');

- relevant in that we do not need to 'repeat, paraphrase, qualify explain, give examples, or use any other kind of redundancy' (Tomlinson, 2000, p. 131);

- very fast (according to Korba (1990) it is ten times faster than outer speech); 
- egocentric ('It is by and for ourselves and does not have to consider anyone else.' (Tomlinson, 2007a, p. 68);

- coherent to the speaker as they are fully aware of their pragmatic intent.

Inner speech does not operate in isolation but typically plays a part in multidimensional representations of meaning (Masuhara, 1998) through 'interaction between inner speech, sensory imagery and affect' (Tomlinson, 2000, p. 125). Without the use of inner speech we would have great difficulty thinking, responding, planning, preparing and understanding. Imagine having to do all that in full grammatical sentences or without language at all. That is the position many L2 learners are in when their L1 inner voice is inhibited and their L2 inner voice is not developed. The more we can help our learners to develop an L2 inner voice and to make use of it in interaction with their L1 inner voice, with sensory images and with affective impulses the better.

\section{What Do We Use the Inner Voice For?}

\section{In the $\mathrm{L1}$}

We use the inner voice to help us to understand and retain in short term memory what we hear and read. The auditory images we hear are stored for a brief time in the phonological store and can be rehearsed (and therefore held for longer) in the phonological loop. The graphic images we see on a page need to be converted into auditory images in the brain in order for comprehension and retention to take place. This is achieved by using the inner voice (sometimes referred to as the articulatory (spoken) code) to pronounce the sounds represented by the words which we have initially processed visually. These acoustic images are then passed on to the phonological store where they can be held briefly and rehearsed in the phonological loop. Auditory images which have been processed in an articulatory code are passed on to Wernecke's area in the brain for matching with words stored in long term memory to achieve comprehension (Schutze, 2017; Tomlinson \& Masuhara, 2020).

Tomlinson (2000, p. 134) conducted research with two groups of English as an L1 speaking students at the National University of Singapore and asked them to monitor their use of inner speech over a day and to write down when they found themselves using inner speech and why they thought they were doing so. Some of the reasons they gave were:

- Preparing to speak to someone.

- Just thinking out my thoughts.

- Helps to relax when tense.

- Reasoning to myself.

- Clarifying doubts.

- Clarifying thoughts.

- Advice to self.

- Reassurance - "I tell myself things which will help me to feel better."

- When feelings at a high level.

- Making remarks on the scenario I imagined. 
Tomlinson (2000. p. 135-142) refers to his research and the research in the literature on the inner voice to elaborate on the following common functions of the L1 inner voice:

- Repeating

- Mental representation

- Connecting

- Responding

- Remembering

- Recalling

- Developing thought

- Planning

- Deciding

- Reassuring

- Preparing for public speech

- Monitoring

The last two are particularly important. We typically develop and rehearse in our inner voice what we intend to write or say in our external voice. We also typically use our inner voice to monitor what we intend to say or write, what we are saying or writing and what we have said or written. How valuable it would be if our learners could use their L2 inner voice to prepare for the use and monitoring of their L2 external voice. Not only could this improve their ability to communicate in their L2 but it could contribute to their acquisition and development of it too. See Tomlinson and Masuhara (2020) for detailed discussion of how this could happen through the provision of auto-input which meets such criteria for acquisition as relevance, meaningfulness, salience, re-cycling, engagement and utility.

Guerrero (2017, p. 6) reports a study by Morin, Uttland Hamper (2011) which revealed that:

the contents of IS were predominantly self-referential; i.e., IS dealt with thoughts about the respondents' own emotions, physical appearance, relationships, and the like. In addition, the most frequently reported functions were self-regulation (planning, controlling emotions), memory (remembering, rehearsing what to say), and problem-solving.

Other research revealing characteristics and functions of inner speech include:

- Steels' (2003) research which demonstrated that inner speech self-monitoring facilitates both effective outer speech and language acquisition as a result, for example of noticing and repairing comprehension failure and then acquiring those features used to achieve effective repair;

- Akhutina's (2003) research which demonstrates how inner speech progresses vague thought towards precise outer speech utterance.

- Bleser and Marshall's (2005) discovery that impaired and/or inhibited inner speech results in unsuccessful outer speech (a situation many L2 learners never recover from). 


\section{In the $\mathrm{L} 2$}

Many researchers claim that L2 learners (especially young children) initially use L2 private speech to help them to learn their L2 before later going on to use L2 inner speech to help them do so. Guerrero (2017) summarises research which indicates this progression. She refers to such researchers as Lee $(2006,2008)$ whose study of seven Korean learners of English revealed they were using private speech for 'establishing meanings; mental rehearsal for memorization; monitoring, planning, and self-motivation; and expressing emotions' (Guerrero, 2017, p. 11). She also refers to Yoshida (2009) whose study of six college learners of Japanese found that they were using private speech for repetition, for responding to questions, for commenting on new words and for practising answers, and she refers to Wang and Hyun (2009) who found that schoolchildren in Taiwan learning English used private speech to memorise words, practise pronunciation, form sentences and rehearse for production. Guerrero (2017) also refers to research which shows that L2 learners often use their L1 together with the L2 when making use of private speech. For example, she refers to Scott and de la Fuente (2008) who revealed that 'English-speaking learners of French and Spanish who were instructed to use only the L2 to conduct an L2 grammar task, nevertheless, talked to themselves in the L1 to translate the text, recall grammar rules, review the task, and plan what to say in the L2' (Guerrero, 2017, p. 12).

While the findings that Guerrero (2017) reports about L2 private speech tally with my own experience of the use of private speech in L2 classrooms. I do not accept them as evidence that the use of private speech necessarily precedes the use of inner speech in L2 learning. My experience is that many L2 learners at early levels are so focused on micro-processing and micro-production of the L2 that they make little use of L2 inner speech or private speech. Eventually though as they gain confidence and competence they begin to make more use of both private speech and inner speech, and especially when encouraged to do so. My informed hunch is that they are more likely to use private speech when they are with other learners (even though the private speech is directed primarily at themselves) and more likely to use inner speech when they are working alone, listening to a teacher or working individually in a silent classroom. My experience is most certainly that L2 learners of all ages and all levels can be guided to make use of L2 inner speech when learning and using the L2, regardless of whether or not they have passed through a previous stage of using private L2 speech.

My view is that the development of inner speech precedes the use of private speech and of external speech in the L1 and then all three continue to interact and develop together. That this is possible and desirable in the L2 is supported to some extent by the work of Arbib $(2012,2015)$ whose main claim is that 'Biological evolution gave us a language-ready brain that made the eventual invention of language possible.' (Arbib, 2015, p. 601). This means that, 'the young can acquire language if raised in a community in which language is used for communication' (Arbib, 2015 , p. 600). I would argue that this is true of L2 learners too if they are 'taught' in a class in which the L2 is used for communication (Tomlinson \& Masuhara, 2020). Arbib (2015) argues that in the evolutionary development of language, pantomime (using descriptive gestures to represent actions) led eventually to protosign (systematic, creative use and combination of 
meaningful gestures, 'a set of conventional gestures used to formalise and disambiguate pantomine' (Arbib, 2015, p. 612). Protosign then eventually led to protospech (a system of 'open-ended semantics' (Arbib, 2015, p. 613) in the evolving language-ready brain). And finally protospeech led to language as a result of the development of a 'neural construction grammar' which was used and developed further by 'both the external social uses of language and the internal cognitive uses of language' (Arbib, 2015, p. 619). Arbib implies that that this evolutionary progress towards the effective use of language is mirrored by the child's progress towards the acquisition of language. I would argue that it can also be mirrored by an L2 learner's progress towards the acquisition of the target language and that the combined use of both internal and external language can facilitate L2 language acquisition from the beginning.

Most researchers have found little evidence of L2 learners making use of their inner voice until they reach quite advanced levels. In a number of experiments, Tomlinson (1996. 1997. 1998) asked both native speakers and L2 intermediate level learners to read short texts and then to reflect on their reading process. The native speakers reported considerable use of both the inner voice and visualisation but the L2 learners did not. Instead, they reported their attempts to decode and translate, as did the L2 learners in Masuhara's (1998) research who were asked to think aloud as they were reading the beginning of a novel. However, a number of researchers (e.g. Appel \& Lantolf (1994), Guerrero (1994), Masuhara (1998), McCafferty (1998), Tomlinson and Avilla, 2007a) found that the advanced learners in their experiments did make use of inner speech and private speech to achieve mental representation as a preparation for production and in the comprehension and recall of texts. My experience has been that lower level L2 learners rarely make use of their inner voice but they can be encouraged and helped to do so.

\section{Researching the Use of Inner Speech}

Researching the use of inner speech is inevitably more difficult than researching the use of private speech as its manifestation is by definition covert. However, a number of indirect research methodologies have been used and they have produced consistent findings.

For example, Guerrero (2004) asked her learners to keep L2 inner speech diaries. Her study yielded several concealed behaviours, such as (in descending order of frequency) inward reproduction of language being heard or read, spontaneous or deliberate recall of language heard or read previously, mental preparation of future language production, imagining conversations in the L2, and silent verbalization of private thoughts.(Guerrero, 2017, p. 5)

Tomlinson (2000) gave sixteen third year BA students at the National University of Singapore a questionnaire which, without them knowing it, was designed to elicit information about their use of the inner voice. All of them were Singaporean and all of them said they used English as an L1. The first task asked them to read the poem 'Have a Nice Day' by Spike Milligan in a relaxed way and reassured them that they would not be asked comprehension questions. After reading the poem they were asked to write down anything they did mentally whilst and just after reading the poem. Twelve of the students reported talking to themselves, ten reported seeing visual images, two mentioned repeating lines of the poem and one said she used different voices for the 
different characters in the poem. The second task was to try to remember what happened in the poem and then they were asked to write down what they did mentally to help them recall the poem. Eleven reported visualising and ten said they talked to themselves. 'One repeated salient phrases, one tried to repeat the conversation in the poem and one imagined retelling the story to somebody else' (Tomlinson, 2000, p.127). The next task involved reading three very short poems and then being asked to write down the exact words they said to themselves whilst reading the poems. Forty seven inner speech utterances were reported by the sixteen students. The final task focused on their use of the inner voice over a particular day. They were asked to note down anything they think they said to themselves and then to complete the questionnaire by saying when they used inner speech, why they used it and what they said. Thirty five different occasions and sixteen reasons for inner speech were reported and twenty eight examples of inner speech utterances were recorded. The examples of inner speech utterances together with examples of Tomlinson's own use of inner speech were then used to begin building a corpus and to form the basis of a categorisation of the characteristics and functions of L1 inner speech.

Morin, Duhnych and Racy (2018) used an open-format thought listing procedure with 76 university students. The most frequently reported inner speech activities were self-regulation (e.g., planning and problem solving), self-reflection and critical thinking, and inner speech occurred most commonly while studying and driving.

Other research methods which have been used to gain information about the characteristics and use of the inner voice include:

- Inhibiting sub-vocalisation during silent reading to discover the effect on comprehension and recall of not using the inner voice. Sokolov (1972), for example, found that his L1 subjects could not remember what they had just read.

- Eliciting private verbal thinking during problem solving tasks (e.g. Centeno-Cortes and Jinenez, 2004).

- Eliciting think aloud protocols during silent reading (e.g. Masuhara, 1998).

- Asking learners to write down anything they find themselves saying to themselves with their inner voice (Tomlinson, 2000).

- Reflecting on the mental processes which were involved whilst reading a page of text (Tomlinson, 1997).

- Providing input to the inner ear to inhibit the use of the outer ear (e.g. Smith et al, 1992).

\section{Why Should We Encourage and Help L2 Learners to Use Their L2 Inner Voice?}

The most obvious, though rarely appreciated, reason for encouraging L2 learners to use their L2 inner voice is because becoming proficient in a new language not only involves developing the ability to read, write, listen and speak in that language but also involves developing the ability to think and to communicate with the self in that language too. As Guerrero (2017, p. 1) says, 'Acquiring a new language implies not only learning how to communicate in it with others, it also involves developing the capacity to use this language covertly for private thinking and selfcommunicative purposes.' 
Other benefits of L2 learners using an L2 (or L2 and L1 combined) inner voice include:

- Gaining massively increased opportunities to both practise and use the L2 without the language anxiety often caused by being monitored and by the fear of failure.

- Gaining auto-input with the potential for facilitating language acquisition and development (Tomlinson \& Masuhara, 2020).

- Being able to play with the language and use it creatively.

- Gaining greater readiness and preparedness to speak and to write as a result of inner speech preparation, rehearsal and monitoring (Tomlinson \& Masuhara, 2020).

- Gaining confidence and self-esteem from perceptions of success.

- Gaining cognitive engagement from the developing ability to think in and about the L2.

- Becoming more likely to be able to read in the L2 with comprehension. A number of researchers have prevented learners from using their inner voice when reading and have demonstrated that this affects their reading comprehension negatively. For example, Kato (2009) found such an effect when conducting research on the inner voice with 64 Japanese learners of English.

\section{Ways of Helping Learners to Orchestrate their Inner Voice for L2 Learning and Use}

It seems that most learners develop an L2 inner voice as they become more proficient in the L2 and as they experience greater exposure to the L2 in use. Shigematsu (2010), for example, came to this conclusion when analysing the self-reports of five L2 learners of English and Japanese. My experience though has been that the development of an L2 inner voice can be accelerated if learners are alerted to its value, if they are stimulated to perform tasks designed to contribute to its development and especially if they are provided with (and provide themselves with) rich and frequent experience of the L2 in communicative use.

\section{In Class}

I know of no mainstream coursebook which includes any advice or suggested activities for encouraging L2 learners to make use of their L2 inner voice. Tomlinson and Avila (2007b) analysed nine mainstream coursebooks and could not find a single activity involving the use of the learner's inner voice. This means that a teacher who believes in the value of increased learner use of their L2 inner voice needs to take the initiative and develop interventions of their own, unless they are using Use Your English (Tomlinson \& Masuhara, 1994), Openings (Tomlinson, 1994), one of the coursebooks developed by a project team led by Brian Tomlinson at Leeds Metropolitan University for China, Ethiopia and Singapore in the early part of this century or a primary school coursebook in South Korea which does include numerous inner speech activities. In this book (see Hegelson, 2001) learners are presented with external speech L2 dialogues and are asked to imagine what the interactants are saying with their inner voices. According to the author in a personal correspondence (in which he enclosed samples of learners' work) these activities have proved very popular and have stimulated unexpected bursts of creativity. I have 
also used similar activities and, for example, have given a coursebook dialogue for learners to act out in character and context in pairs, in groups and sometimes as a whole class with one half playing one character and the other half playing the other character. Such an activity involved acting out a stereotypical shoe shop dialogue between a salesman and a customer which I brought to life by adding the information that they had recently got divorced and neither expected to meet the other in the shoe shop. After acting out the script provided, with the addition of their meaningful pauses, tone of voice, volume and intonation, they wrote down in pairs the inner speech they imagined the characters using. For example, the salesman on first realising the customer was his ex-wife saying to himself, 'Oh not you!' before saying aloud, 'Good morning Madam.'

Here are some other suggested teacher interventions in the classroom.

My main advice would be to avoid forcing learners into premature production of the L2. Most coursebooks and most courses push beginners into producing in the L 2 from the very beginning. The processing energy required to do this can inhibit the use of the L1 inner voice and prevent the development of an L2 inner voice. However if a comprehension approach is followed initially then learners are allowed more thinking time during which they can make use of visualisation and of their L1 inner voice to comprehend and process the language they are exposed to and they can begin to develop an L2 inner voice which they can use without fear of correction. A comprehension approach (Barnard, 2007; Postovsky, 1981; Winitz, 1981) is one which exposes the learners to the L2 in contextualised use through listening to stories and other aural texts before responding to them in the L1, drawing their responses or miming them (as in TPR Plus (Tomlinson, 1990, 1994b), an approach in which, for example, the teacher tells a dramatic story and all the learners mime it as they listen to it).

Tomlinson \& Avila (2007b, p. 84)) say that:

One way of helping learners to develop L2 inner voices is to offer beginners an initial silent period of experiencing the language in contextualised use without having to focus on the correct features of the L2 outer voice or to produce any utterances publicly. They can then be given problem solving tasks to do .... and be encouraged to use inner speech, private speech, visual imaging, drawing and physical movement to help them to articulate and solve the problems.

This is a very good way of promoting the use of L1 inner speech and beginning the early development of an L2 inner voice. Ways of preventing the development of an L2 inner voice thought are prevalent and include the teacher:

- forcing premature production of the L2;

- talking to the learners only in planned and formal speech rather than chatting to them in colloquial speech (which, as Vygostsky (1956) says, is close to inner speech);

- focusing on drills and controlled practice activities which 'can prevent the development of inner speech as they do not allow time for thought, do not offer any problems to think about and focus the learner's attention on correct forms of outer speech' (Tomlinson \& Avila (2007b, p. 84); 
- introducing "premature reading activities in which the learner is forced to focus processing energy on low level linguistic decoding of a short and empty text in order to answer discrete comprehension activities focusing on the linguistic code of outer speech' (Tomlinson \& Avila (2007b, p. 85);

- focusing on and insisting on accurate use of written grammar whenever the learner is asked to write or speak.

I have found it to be very useful to talk to the learners about the existence and value of the inner voice and to suggest they develop an L2 inner voice and use it as often as possible. I would repeat this advice frequently and set thinking tasks for them to do in their L2. For example, when using the text-driven approach (TDA) (Tomlinson, 2013, Tomlinson \& Masuhara, 2018) I would set a mental readiness activity for the learners to do prior to encountering the core text. An example would be before reading a poem aloud to the class about a boy's first day at school to ask the learners to visualise their own first day at school and then to talk to themselves about how they felt on leaving home, on arriving at the school, on meeting their first teacher and during their first lesson. This readiness activity not only has the benefit of promoting the use of the inner voice but also of connecting the text to the learner's experience and of stimulating affective engagement, both important determiners of intake in the process of acquisition (Tomlinson \& Masuhara, 2020).

I would also advise teachers of lower proficiency levels to pause for ten seconds after asking a question in the L2 to the class to allow the learners to prepare an inner speech answer before inviting them to share their answers externally with a group or the class. Bao $(2013,2014)$ did this with students when researching L2 oral reticence among Vietnamese learners of English and he found that this led to a considerable increase in the number and quality of answers. I would also advise teachers to encourage their learners to read the text to themselves with their inner voice when engaged in silent reading as this ensures that the graphic images on the page are converted into the auditory images required by Wernike's area in the brain for the achievement of comprehension. It can also make the input more meaningful to the learner and more likely to become intake with the potential for contributing to acquisition (Tomlinson \& Masuhara, 2020). Amazingly many courses advise against what they call sub-vocalisation on the grounds that it slows down the reading. This might be true but not using the inner voice when reading silently also halves the time that an utterance is retained, inhibits comprehension and considerably reduces the likelihood of intake and eventual acquisition.

Guerrero (2017, p. 24) recommends the integration of subvocal repetition or rehearsal in pedagogical activities. She refers to Borer (2007), who found positive results in the implementation of learners' use of self-vocalization in the learning of L2 vocabulary and quotes Borer's (2007, p. 287) finding that 'by selectively rehearsing linguistic features such as phonology, spelling, or meaning for future use, learners began the transformation from external to inner speech' (2007: 287). She also refers to Fallahchai (2011) who found that helping learners to develop phonological awareness and to engage in vocal and subvocal rehearsal facilitated the learning of foreign language words. In addition, Guerrero (2017, p. 25) 
recommends a shadowing activity which consists' of repeating segments of a text in three modes-out loud, low voice, and silent (subvocal)', thus providing opportunities for internalisation and also describes a dialogue journal writing activity recommended by Mahn (2008) in which learners write dialogues whilst focusing on meaning and not worrying about making mistakes. As Mahn (2008, p. 122) says, 'When students focus on meaning and are relieved of the pressure of producing errorfree writing, they increasingly rely on inner speech and verbal thinking'.

Tomlinson (2001) recommends offering learners an initial silent period during which they are not required to respond to experiencing the use of the L2 with their external voice but are encouraged to respond to it with a mixture of their L1 inner voice and an emerging L2 inner voice. He also suggests that learners should do TPR Plus activities (Tomlinson, 1994b) in which learners respond to L2 instructions with their inner voice before responding to them physically and he recommends among other activities reading extensive readers silently whilst talking to themselves with their inner voices about what they are reading. Tomlinson (2003) also recommends getting learners to read extensive readers and (at higher levels) authentic literature but does so in order to expose them to the use of realistically simple inner speech in narrative texts as a way of prompting their own use of inner speech.

In class activities which Tomlinson and Avila (2007b, p. 83) recommend to help the development and use of an L2 inner voice include:

- "Readiness activities which stimulate relevant mental activities prior to reading or listening to a text (e.g. "See pictures in your mind of an interesting old lady you know and talk to yourself about why you find her interesting.")."

- "Intake response activities which facilitate the development of personal responses to a text which has just been read or listened to (e.g. 'Do you like the old lady/Give yourself reasons for your answer)."

- "Development activities in which the learners visualise a localized version of the text they have just read prior to telling the new story to themselves mentally as a preparation for telling (or writing) the story to somebody else."

- "Creating mental picture stories and descriptions prior to turning them into inner voice texts."

- "Extensive reading of stories which include samples of inner speech and/or encourage visual imaging and inner speech."

- "Mentally preparing and rehearsing for participation in conversation or to give an unscripted presentation."

- "Engagement in natural, colloquial discourse with teachers and other proficient users (Di Camilla \&Anton, 2004)."

Many of these recommended activities feature in the Text Driven Approach (TDA) (Tomlinson, 2013; Tomlinson \& Masuhara, 2018), an approach which makes use of a potentially affectively and cognitively engaging text to drive multi-dimensional activities designed to 
facilitate language acquisition. You might have noticed that many of the recommended activities also involve the learners making use of visualisation.

\section{Out of Class}

When I was teaching approximately B1 level students at Kobe University I used to set them L2 inner voice homework tasks. These included:

- Looking out of the window on the bus or train on the way home and mentally rehearsing a commentary on the moving scene as though it was for a television documentary.

- Observing people who are in conversation and mentally reproducing an imagined conversation between them.

- Selecting a fellow passenger and having an inner voice conversation with them.

Other such tasks could include:

- Setting aside a day each week in which a mixture of L1 and L2 inner speech will be used.

- Setting aside a time of the day when the learner tries to only use their L2 for conversations with themselves.

- Keeping an L2 inner speech diary in which samples are noted just after they are uttered and comments are made about the use during the day of L2 inner speech.

- Repeating in the inner voice any L2 utterances heard or read out of class (preferably with visual images representing the meaning and intention of the utterance).

- Meeting a fellow L2 learner, deciding on a topic for an L2 discussion and then spending ten minutes in silent inner speech preparation for the discussion. Holding the discussion and then later attempting to recreate it internally with the inner voice. Writing down the inner speech recreation of the discussion and then sharing it with the other learner by email.

\section{The Inner Voice and Visualisation}

As mentioned earlier in this article the inner voice is often used in the L1 in conjunction with visualisation in conversation with the self, in the comprehension of spoken or written language and in the preparation for and monitoring of language production. Evidence for this concurrent use of the two mental processes is provided in the research of Leontiev and Ryabova (1981) and of Sadoski and Paivio (1994), as well as in a number of inner voice diaries (e.g. Tomlinson (2003); Wiley (2006)). There is little evidence that this is normal though in L2 processing and production but some evidence that it can be successfully encouraged (Tomlinson \& Avilla, 2007a, 2007b).

For more information about the role of visualisation in language use and acquisition see Tomlinson (2011), Tomlinson and Avila (2007a, 2007b), Tomlinson and Masuhara (2018, 2020). 


\section{Conclusion}

I have no doubt that most learners of an L2 make insufficient use of their inner voice to help them to acquire the L2 and to communicate effectively in it. I also have no doubt that being encouraged to use their inner voice more through teacher information, guidance and setting of tasks would help them to become more effective acquirers and users of the language.

You could try following some of the advice and setting some of the activities suggested in this article and see what happens.

\section{Further Reading}

Guerrero, M. C. M. de (2017). Going covert: Inner and private speech in language learning.

Language Teaching, 51(1), 1-35. doi:10.1017/S0261444817000295

Tomlinson, B. (2001). The inner voice: a critical factor in language learning. Journal of the Imagination in L2 Learning, VI, 26-33.

Tomlinson, B. (2003). Helping learners to develop an effective inner voice. RELC Journal, 43(2), 178-194.

Tomlinson, B. \& Avila, J. (2007b). Applications of the research into the roles of audio-visual mental for language teaching pedagogy. In B. Tomlinson (Ed.), Language acquisition and development: Studies of learners of first and other languages (pp. 82-89). London: Continuum

\section{References}

Arbib, M. A. (2015). Language evolution: An Emergentist perspective. In B. MacWhinney \& W. O’Grady (Eds.), The handbook of language emergence (pp. 600-624). Chichester: Wiley Blackwell.

Akhutina, T. V. (2003). The role of inner speech in the construction of an utterance. Journal of Russian and Eastern European Psychology, 41(3/4), 49-74.

Appel, G. \& Lantolf, J. P. (1994). Speaking as mediation: A study of L1 and L2 text recall tasks. The Modern Language Journal, 78(4), 437-452.

Bao, D. (2013).Voices of the reticent: Getting inside views of Vietnamese secondary school students on learning. In M. Cortazzi \& L, Jin (Eds.), Researching cultures of learning: International perspectives on language learning and education (pp. 136-154). Basingstoke: Palgrave Macmillan.

Bao, D. (2014). Understanding silence and reticence: Ways of participating in second language acquisition. London: Bloomsbury.

Barnard, E. S. (2007). The value of comprehension in the early stages of acquisition of Bahasa Indonesia by nonnative speakers. In B. Tomlinson (Ed.), Language acquisition and development: studies of learners of first and of other languages(pp. 187-204). London: Continuum.

Bleser, R. de \& Marshall, J. C. (2005). Egon Wegl and the concept of inner speech. Cortex,41(2), 249-257.

Borer, L. (2007). Depth of processing in private and social speech: Its role in the retention of word knowledge by adult EAP learners. The Canadian Modern Language Review/La Revue Canadienne des Langues Vivantes, 64(2), 273-300.

Centeno-Cortes, B. \& Jimenez, A. F. (2004). Problem solving tasks in a foreign language: the importance of the L1 in private verbal thinking. International Journal of Applied Linguistics, 14(1), 7-5.

Di Camilla, F. J. \& Anton, M. (2004). Private speech: a study of language for thought in the collaborative interaction of language learners. International Journal of Applied Linguistics, 14(1), 36-69.

Fallahchai, R. (2011). The effects of use of learning strategies training on students' foreign language vocabulary learning. International Journal of Scientific Research in Education,4(3/4), 181-189. 
Guerrero, M. C. M. de (2004). Early stages of L2 inner speech development: what verbal reports suggest 1. International Journal of Applied Linguistics, 14(1), 90-112. doi:10.1111/j.1473-4192.2004.00055.x

Guerrero, M. C. M. de (2005). Inner speech - L2: Thinking words in a second language(Vol. 6). Boston, MA: Springer US.

Guerrero, M. C. M. de (2017). Going covert: Inner and private speech in language learning. Language Teaching, 51(1), 1-35. doi:10.1017/S0261444817000295

Hegelsen, M. (2001). Inner voice, time, planning and practice, www.mgu.ac.jp/-ic/helgesen2/paper.htm

Kato, S. (2009). Suppressing inner speech in ESL reading: Implications for developmental changes in second language word recognition processes. The Modern Language Journal,93(4), 471-488.

Korba, R. J. (1990). The rate of inner speech. Perceptual and Motor Skills, 71, 1043-1052.

Lantolf, J. P. (2003). Intrapersonal communication and internalization in the second language classroom. In A. Kozulin, B. Gindis, S. M. Miller, \& V. S. Ageyev (Eds.), Vygotsky's educational theory in cultural context (pp. 349-370). Cambridge: Cambridge University Press.

Lee, J. (2006). Talking to the self: A study of the private speech of adult bilinguals. Ph.D. dissertation, University of Wisconsin-Madison.

Lee, J. (2008). Gesture and private speech in second language acquisition. Studies in Second Language Acquisition, 30(2), 169-190.

Mahn, H. (2008). A dialogic approach to teaching L2 writing. In J. P. Lantolf \& M. E. Poehner (Eds.),Sociocultural theory and the teaching of second languages (pp. 115-138). London: Equinox.

Masuhara, H. (1998). Factors influencing the reading difficulties of advanced learners of English when reading authentic texts. Unpublished PhD. Thesis. University of Luton.

Morin, A., B. Uttl, B.\& Hamper, B. (2011). Self-reported frequency, content, and functions of inner speech. Procedia-Social and Behavioral Sciences 30, 1714-1718.

Morin, A., Uttl, B., \& Morin, N. C. A. (2013). Inner speech a window into consciousness. The Neuropsychotherapist. DOI: 10.12744/tnpt.14.04.2013.01

Morin, A., Duhnych, C. \& Racy, F. (2018). Self-reported inner speech use in university students. Applied Cognitive Psychology, 1-7.

Postovsky, V. A. (1981). The priority of aural comprehension in the language acquisition process. In H. Winitz (Ed.), The comprehension approach to foreign language instruction. Rowley, MA: Newbury House.

Resnik, P. (2018). Multilinguals' use of L1 and L2 inner speech. International Journal of Bilingual Education and Bilingualism, 1-19. doi:10.1080/13670050.2018.1445195

Schutze, U. (2017). Language learning and the brain. Cambridge: Cambridge University Press.

Scott, V. M. \& M. J. de La Fuente, M. J. (2008). What's the problem? L2 learners' use of the L1 during consciousness-raising, form-focused tasks. The Modern Language Journal, 92(1), 100-113.

Shigematsu, B. K. (2010). Second language inner voice and identity. Ph.D. dissertation, University of Nevada, Las Vegas.

Smith, J. D., Reisberg, D. \& Wilson, M. (1992). Subvocalisation and auditory imagery: Interactions between the inner ear and the 'inner voice'. In D. Reisberg (Ed.), Auditory imagery. Hillsdale, NJ: Lawrence Erlbaum.

Sokolov, A. N. (1972). Inner speech and thought. New York: Plenum Press.

Steels, L. (2003). Language re-entrance and the "inner voice". Journal of Consciousness Studies, 10(4/5), 173-185.

Tomlinson, B. (1990). Managing change in Indonesian high schools. ELT Journal, 44(1), 25-37.

Tomlinson, B. (1994a). Openings Language through literature: an activities book. London: Penguin. 
Tomlinson, B. (1994b). TPR materials. Folio 1(2), 8-10.

Tomlinson, B. (2000). Talking to yourself: The role of the inner voice in language learning. Applied Language Learning, 11(1), 123-154.

Tomlinson, B. (2001). The inner voice: a critical factor in language learning. Journal of the Imagination in L2 Learning, VI, 26-33.

Tomlinson, B. (2003). Helping learners to develop an effective inner voice. RELC Journal, 43(2), 178-194.

Tomlinson, B. (2011). Seeing what they mean: Helping learners to visualise. In B. Tomlinson (Ed.), Materials development in language teaching ( $2^{\text {nd }}$ edn., pp. 257-278). Cambridge: Cambridge University Press.

Tomlinson, B. (2013). Developing principled frameworks for materials development. In B. Tomlinson (Ed.), Developing materials for language teaching (2 ${ }^{\text {nd }}$ edn., pp. 95-118). London: Bloomsbury.

Tomlinson, B. \& Avila, J. (2007a). Seeing and saying for yourself: The role of audio-visual mental aids in language learning and use. In B. Tomlinson (Ed.), Language acquisition and development: Studies of learners of first and other languages (pp. 61-81). London: Continuum.

Tomlinson, B. \& Avila, J. (2007b). Applications of the research into the roles of audio-visual mental for language teaching pedagogy. In B. Tomlinson (Ed.), Language acquisition and development: Studies of learners of first and other languages (pp. 82-89). London: Continuum.

Tomlinson, B. \& Masuhara, H. (1994). Use your English. Tokyo: Asahi Press.

Tomlinson, B. \& Masuhara, H. (2018).The complete guide to the theory and practice of materials development for language learning. Holboken, $\mathrm{NJ}$ : Wiley.

Tomlinson, B. \& Masuhara, H. (2020). SLA applied: Connecting theory and practice. Cambridge: Cambridge University Press.

Vygotsky, L. S. (1956). Thought and language. In Selected Psychological Investigations. Academic Pedagogy of Science: Moscow: RSFSR Press.

Vygotsky, L. S. (1986). Thought and language. Cambridge, MA: MIT Press.

Wang, H.-C., \& Shih, S.-C. (2011). The role of language for thinking and task selection in EFL learners' oral collocational production. Foreign Language Annals, 44(2), 399-416. doi:10.1111/j.1944-9720.2011.01135.x

Wang, L. \& Hyun, E. (2009). A study of sociolinguistic characteristics of Taiwan children's peer-talk in a Mandarin-English-speaking preschool. Journal of Early Childhood Research, 7(1), 3-26.

Wiley, N. (2006). Inner speech as a language: A Saussurean inquiry. Journal for the Theory of Social Behaviour. $36(3), 319-341$.

Winitz, H. (Ed.). (1981). The comprehension approach to foreign language instruction. Rowley, MA: Newbury House.

Yoshida, R. (2009). Learners in Japanese language classrooms. Overt and covert participation. London: Continuum. 